\title{
REDESCUBRIMIENTO Y ASIMILACIÓN DE LA DOCTRINA ARISTOTÉLICA EN TOMÁS DE AQUINO Rubén Betancourt*
}

RESUMEN: En este artículo se reflexiona acerca de algunos elementos importantes en torno a la "relación" entre la doctrina de Aristóteles y Tomás de Aquino. En concreto, son tres los temas que nos interesan aquí y que encabezan cada uno de los apartados del desarrollo sistemático de este trabajo: (1) el panorama cultural que enfrenta Tomás de Aquino respecto al redescubrimiento de Aristóteles, (2) la descripción de cada una de las obras que comentó el Aquinate y (3) algunas conclusiones que se desprenden como "matices" para tener en cuenta y juzgar rectamente la relación entre estos pensadores.

\author{
9ose \\ REDISCOVERY AND ASSIMILATION OF THE ARISTOTELIAN \\ DOCTRINE IN THOMAS AQUINAS
}

ABSTRACT: This article reflects on some important elements in the "relationship" between the doctrine of Aristotle and Thomas Aquinas. In particular, there are three subjects that interest us here and serve as head of each one of the sections of the systematic development of this work: (1) the cultural panorama Thomas Aquinas faces regarding the rediscovery of Aristotle, (2) the description of each one of the works that Aquinas commented on, and (3) some conclusions that are drawn as "nuances" in order to take into account and righteously judge the relationship between these thinkers.

Palabras ClaVe: Aristóteles, Edad Media, escolástica, Averroes, Avicena, Maimónides, Alberto Magno.

KEY WORDS: Aristotle, Middle Ages, scholastic, Averroes, Avicenna, Maimonides, Alberto the Great.

*Universidad Pontificia de México. 
CITAM Derechos Reservados.

La reproducción total o parcial de este artículo se podrá hacer si el ITAM otorga la autorización previamente por escrito.

RECEPCIÓN: 15 de diciembre de 2016.

APROBACIÓN: 13 de enero de 2017.

Estudios 121, vol. XV, verano 2017. 


\title{
REDESCUBRIMIENTO Y ASIMILACIÓN \\ DE LA DOCTRINA ARISTOTÉLICA EN TOMÁS DE AQUINO
}

\section{Panorama cultural de Tomás de Aquino}

\begin{abstract}
Discípulos y estudiosos de la doctrina aristotélica (griegos, romanos, bizantinos y árabes) dedican sus esfuerzos a tratar de comprender el pensamiento del Filósofo y realizan importantes aportaciones a manera de comentarios. La historia da testimonio de que siempre hay motivos para comentar a Aristóteles. ${ }^{1} \mathrm{El}$ "prestigio" de la figura de Aristóteles no se ha apagado, aun cuando, en ocasiones, los rayos de su sabiduría queden opacados por las "malas interpretaciones" de sus lectores. ${ }^{2}$ La actualidad de su pensamiento es un dique que se levanta por sí mismo, dada la profundidad especulativa de su doctrina, siempre nueva como actual, desde el punto de vista que se le quiera abordar. Una generación tras otra, sobre todo la medieval, han recogido sus ecos. Conforme avanza la ciencia, el Estagirita ha tenido algo que decir y ha ocupado la primera fila en las investigaciones de las ciencias naturales y humanísticas. El prodigio de su mente llegó al culmen de las ponderaciones metafísicas, de tal manera que, para entenderlo, hay que elevarse; y esto cuesta mucho trabajo, es complejo y de un rigor metafísico tan alto, que pocas mentes son capaces de comprender. ${ }^{3}$

${ }^{1}$ Luis López Farjeat, Teorias aristotélicas del discurso, 2002, Pamplona, EUNSA, p. 23.

${ }^{2}$ Richard Heinzmann, Filosofia de la Edad Media, 1995, Barcelona, Herder, p. 362.

${ }^{3}$ Josep-Ignasi Saranyana, La filosofia medieval, 2003, Pamplona, EUNSA, pp. 272-273.
\end{abstract}


Tomás de Aquino continuó y llevó a término la obra iniciada por Alberto Magno. Gracias a estos pensadores, el aristotelismo se hizo flexible y dócil a todas las necesidades de la explicación dogmática, y no mediante ocasionales adaptaciones artificiales, sino mediante una lógica rigurosa y segura. ${ }^{4} \mathrm{El}$ Aquinate contaba con un talento filosófico nada común. Estaba convencido de que el Estagirita llegó al culmen de la investigación filosófica y que más allá solo quedaba la verdad sobrenatural de la fe. De este modo, tomó el aristotelismo por el camino opuesto al que le hizo seguir la filosofía musulmana. ${ }^{5}$ En la Edad Media, la metafísica de Aristóteles había sido transmitida con ideas y concepciones neoplatónicas, pues ambas tradiciones estaban mezcladas. ${ }^{6}$

\section{El redescubrimiento de Aristóteles} de pensadores árabes y judios

Una de las razones por las que la doctrina aristotélica estuvo oculta varios siglos puede ser su "profundidad especulativa", pues los mismos padres de la Iglesia fueron ajenos a esa doctrina. Hubo que esperar hasta los pensadores medievales para redescubrir a Aristóteles. Así como en la naturaleza se dan los procesos de crecimiento, también en la historia de las ideas, el conocimiento de las esencias de las cosas es lento y progresivo. Con el paso del tiempo, la comprensión del mundo se perfecciona y permite ver con claridad la toma de sentido de la realidad.

En el siglo v ya era conocida la Lógica de Aristóteles, que los medievales llamaban Logica vetus: las Categorías, el De Interpretatione y algunos fragmentos de textos, todos en versión latina. La lógica estaba emparentada en ese siglo con la retórica y la gramática, y se expresaba con un método peculiar: los comentarios a los textos. Sin embargo, no fue en el ámbito filosófico en el que se recuperaron algunas obras

${ }^{4}$ Clemens Vansteenkiste, "El método de santo Tomás", en Tomás de Aquino, también hoy, 1990, Pamplona, EUNSA, p. 100.

${ }^{5}$ Gemma Muñoz Alonso (dir.), Desarrollo de la filosofía patrística. La escolástica, 1988, Barcelona, Sarpe, pp. 235-236.

${ }^{6}$ Gregorio Celada Luengo, Tomás de Aquino, testigo y maestro de la fe, 1999, Salamanca, San Esteban, p. 175. 
del Estagirita, sino en el teológico, en el que los estudios estaban dedicados al trivium y quadrivium, que más adelante se convertirían en colecciones de glosas y comentarios, como se verifica en el Aquinate. La intuición de los pensadores cristianos de guardar la sabiduría de sus antepasados en sentencias, fue una de las más grandes contribuciones para la cultura posterior, que aun en nuestros días siguen siendo útiles y fuentes imprescindibles para la investigación de la Antigüedad. No obstante, la enseñanza aristotélica quedó relegada a sumas o cadenas de síntesis o compendios. El puesto que se le dio fue muy sencillo, como de pensador difícil, cuya aportación esencial fue la Lógica. Al parecer, los pensadores medievales conocían bien a Aristóteles, pero durante largo tiempo se le consideró básicamente como un lógico. Tenían las traducciones al latín de la Lógica pero no poseían el conjunto del corpus aristotelicum. $^{7}$

En el siglo XII, filósofos eminentes de las escuelas o centros de traducción como en Palermo y Toledo, centraron su atención en la producción literaria de la Lógica aristotélica. Hacia 1128 Jaime de Venecia tradujo del griego al latín los libros de los Analíticos, los Tópicos y los Argumentos sofísticos. Entre tanto, avanzó la argumentación lógica. Ya no era la logica vetus, sino la logica nova, y su enseñanza era obligatoria en todos los centros de estudios superiores. Los académicos medievales pudieron contar con un nuevo y poderoso instrumento para la argumentación y la dialéctica, que más adelante, en la Escolástica, fue un modo de vida académica. En el siglo XIII, gran parte del trabajo de traducción en Toledo fue proporcionar a la cultura del tiempo versiones de los más importantes científicos y filósofos griegos. Así surgió el interés por el estudio de la naturaleza y se tradujeron la Física y la Ética. ${ }^{8}$ La Metafísica tuvo que esperar años para ejercer influencia en el mundo medieval. Antes de las traducciones en árabe, en el siglo XIII ya había una en latín y una parcial en griego. La versión que utilizó (incompleta) Tomás de Aquino como estudiante fue la misma que Alberto Magno tuvo en sus manos. Hasta después de 1260, gracias al

${ }^{7}$ Frederick Copleston, El pensamiento de Santo Tomás, 2001, México, FCE, p. 66.

${ }^{8}$ Mauricio Beuchot, Los principios de la filosofía de santo Tomás, 2002, México, IMDOSOC, p. 10. 
dominico Guillermo de Moerbeke, amigo del Aquinate, se elaboró una traducción completa y fidedigna.

Asimismo, en el siglo XIII la obra completa de Aristóteles ya circulaba en las universidades, aunque no sin cierta confusión y mezcla de doctrinas extrañas o contradictorias introducidas por traductores filósofos árabes o judíos. De aquí en adelante, las obras de Aristóteles fueron un factor determinante y decisivo para la teología y la filosofía católica medievales. La labor de integración del aristotelismo a la síntesis escolástica fue encabezada por los grandes dominicos Alberto Magno y Tomás de Aquino, que pusieron la filosofía de Aristóteles al servicio de la doctrina sagrada. Las prohibiciones en ningún momento frenaron el entusiasmo por las nuevas doctrinas, sino que realmente eran "profesionales" en su misión de vivir la verdad ${ }^{9}$ y en la tarea de construir una síntesis teológico-filosófica de la escolástica aristotélica. El Doctor Angélico bien podría considerarse en su época como un "innovador", un pensador "progresista".

Desde el punto de vista académico, la intromisión de la doctrina aristotélica causó crisis y situaciones complejas, ya sea por los teólogos y filósofos más conservadores, como por las autoridades eclesiásticas que miraban con recelo y "prudencia intelectual", el uso de las tesis aristotélicas. ${ }^{10}$ Hay que decir que hubo prohibiciones y condenas, que son comprensibles porque en el ambiente cultural dominaban las ideas platónico-agustinianas, mientras que las ideas de Aristóteles estaban platonizadas por la intervención de los comentaristas árabes y judíos. Es un hecho histórico que la cultura árabe fue el canal principal para la introducción en Occidente de las obras de Aristóteles. Los comentarios de Averroes y Avicena tuvieron mucho de originales, pero también modificaron y mezclaron muchas ideas de Aristóteles, sobre todo por la manera de ver el mundo desde el punto de vista de la doctrina árabe.

Avicena es un caso particular en la recepción del aristotelismo mediado por el neoplatonismo. En la historia de la filosofía, Avicena se presenta como el más importante mediador entre las expresiones teoló-

${ }^{9}$ Francisco Canals Vidal, Historia de la filosofia medieval, 1992, Barcelona, Herder, p. 213.

${ }^{10}$ Leonardo Polo, Nominalismo, idealismo y realismo, 1997, Pamplona, EUNSA, p. 188. 
gicas del cristianismo y los conceptos metafísicos de Aristóteles. Gracias a Avicena se precisaron los conceptos y la terminología que luego fueron enriquecidos por los comentadores aristotélicos cristianos. ${ }^{11}$ El filósofo cordobés Averroes (llamado por Tomás, el Comentador), hizo que Aristóteles fuera conocido y valorado en los ámbitos académicos europeos. Este filósofo musulmán influyó con sus interpretaciones para que los miembros del magisterio eclesiástico previnieran a sus doctores sobre el peligro de una "falsa interpretación". No obstante, Averroes fue un erudito de primera línea. Estudió teología, medicina, jurisprudencia y filosofía, y ocupó cargos importantes como juez y médico de la corte del Califa. Gran parte de su vida intelectual la consagró a traducir y comentar las obras de Aristóteles. Fue perseguido por hermanos de religión conservadores y ortodoxos y tuvo que partir al destierro en Marruecos, donde permaneció hasta su muerte a los 72 años. ${ }^{12}$

Otro exiliado por sus hermanos de religión, pero ya no musulmán sino judío, fue Maimónides, nacido en El Cairo. Consideraba a Aristóteles el más alto ejemplo de inteligencia humana, el hombre más grande de todos los tiempos, antes que Moisés y los profetas. Es interesante cómo Maimónides pensaba que en la Biblia se encuentran "demostraciones racionales" para ayudar al intelecto a fundamentar la vida de fe. Así pues, para él la mente humana es iluminada por la fe bíblica, que acrecienta sus capacidades y la dispone para recibir la gracia de Dios. La tarea de Tomás de Aquino respecto de los pensadores citados fue la de discernir las falsas interpretaciones de la doctrina aristotélica hechas por árabes y judíos. Se puede decir que la labor académica del Aquinate consistió en realizar una "depuración” de la recta doctrina del Estagirita. Antes de Tomás de Aquino, los pensadores medievales no tenían textos críticos de las obras de Aristóteles, ni mucho menos tenían claras sus relaciones con la filosofía de Platón.

Tomás de Aquino no asumió el aristotelismo con una actitud ecléctica ni llevado por la presión del ambiente cultural de su tiempo, sino

${ }^{11}$ Óscar Jiménez Torres, Elementos de las ciencias demostrativas en Aristóteles, 2006, Pamplona, EUNSA, p. 23.

${ }^{12}$ Guillermo Fraile, Historia de la filosofía II (2 $\left.2^{\mathrm{a}}\right)$. Filosofía judia y musulmana. Alta escolástica: desarrollo y decadencia, 2005, Madrid, BAC, p. 27. 
que lo aceptó con la conciencia de incorporar a la filosofía lo que tuviera de verdadero. Según Canals Vidal, ${ }^{13}$ el Aquinate "depuró" la doctrina de Aristóteles de los puntos que consideraba contaminaciones de los comentaristas. La compatibilidad del aristotelismo con una correcta doctrina teológica no era para el Aquinate sino la armonía de la verdad revelada con la verdad racionalmente cognoscible. En la opinión de Mauricio Beuchot, Tomás de Aquino fue el más grande sistematizador del aristotelismo cristiano, pues aprovechó su filosofía para sus construcciones teológicas, añadiendo una multitud de aportaciones originales. ${ }^{14}$

Después de las obras de la Lógica de Aristóteles, penetró en Occidente, en la rígida cultura medieval, el libro de la Física, que mantenía una connotación del movimiento continuo, sin principio ni fin, que posibilitaba la idea de la eternidad del mundo y cuestionaba la enseñanza de la Iglesia sobre la creación. Otra obra que examinaron los medievales es el tratado De anima, en la que Aristóteles relacionaba la teoría hilemórfica a la cuestión del alma y cuerpo, como la materia y la forma, y terminaba por poner en duda el dogma de la inmortalidad del alma. Por último, la Ética Nicomaquea consignaba códigos de conducta humana de tipo temporal y terrenal, sin considerar la enseñanza bíblica del obrar sobrenatural por medio de la gracia y la apertura a la bienaventuranza. Los grandes temas de la doctrina aristotélica tenía que ser revisada a la luz de la fe católica.

\section{Asimilación del aristotelismo: prohibición, tolerancia y recomendación}

La aplicación de la Lógica aristotélica en las universidades europeas había alarmado a los pensadores más ortodoxos; sin embargo, fue el inicio de su creciente autoridad. ${ }^{15} \mathrm{Al}$ no ser Aristóteles un filósofo cris-

${ }^{13}$ Canals Vidal, op. cit., p. 225.

${ }^{14}$ Mauricio Beuchot, Historia de la filosofía medieval, 2013, México, FCE, p. 136.

${ }^{15}$ En la época de Boecio, la Lógica de Aristóteles pertenecía al patrimonio cultural de las escuelas occidentales. El proyecto de Boecio fue maravilloso: "Si la divinidad me ayudare con su poderoso auxilio, este es mi firme proyecto: traduciré a la lengua romana todas las obras de Aristóteles que lleguen a mis manos, junto con todos sus comentarios; y así, todo lo que del sutil 
tiano y por haber sido traducido y comentado por filósofos musulmanes, causaba ciertas sospechas. A pesar de ello, su autoridad a finales del siglo XII ya estaba emparentada con la Biblia y los padres de la Iglesia. La primera condena que se conoce fue la del obispo de Sens en 1210, en un concilio provincial de París. Allí se prohibió, bajo pena de excomunión, la enseñanza pública o privada de la metafísica y la filosofía natural de Aristóteles y sus comentadores. ${ }^{16}$

La universidad de París, el centro más grande y prestigioso de la época, incluyó en sus estatutos de 1215 la prohibición de leer los libros de Aristóteles de la Metafísica, la Psicología y algunos tratados cosmológicos, así como los compendios realizados por cristianos o musulmanes, que según el concilio provincial de París pasaban a ser herejes. Hay que decir aquí algo que omiten muchos manuales de filosofía medieval, que la Lógica y la Ética aristotélicas no estaban vetadas.

La reacción del papa Gregorio IX ante la prohibición del concilio provincial de París no fue muy favorable. Sin desautorizar al obispo de Sens, en 1231 mandó organizar una comisión de teólogos compuesta por Guillermo de Auxerre, Esteban de Provins y Simón de Authie, para que estudiara detalladamente los libros prohibidos de Aristóteles. En el fondo estaba la "honestidad intelectual" y "amor a la verdad", lo que suponía que los escritos aristotélicos valían la pena de estudiarse para dilucidar su ortodoxia, pues sus ideas merecían la atención de los especialistas. Después de un tiempo, la Santa Sede desatendió las condenas a las obras de Aristóteles de 1210 y 1215, desvinculándolas como desviaciones heréticas o peligrosas. Así, el aristotelismo siguió difundiéndose y ganando más autoridad entre los filósofos medievales, preferentemente los pensadores cristianos. Tomás de Aquino contribuyó a determinar la autenticidad de algunas obras aristotélicas, como el Liber de causis y

arte de la lógica, de la gravedad de los juicios morales, y de la agudeza de los estudios científicos haya escrito Aristóteles, lo transferiré ordenadamente y lo ilustraré con comentarios. Del mismo modo, pretendo dar la nueva forma a los diálogos de Platón, vertiéndolos al latín y comentándolos. Hecho esto, no cejaré en el empeño de concertar las doctrinas de Aristóteles y Platón, demostrando además que no disienten en todo ni la mayoría de las veces, sino que, al contrario, concuerdan en las máximas cuestiones filosóficas". Véase Alfonso García Marqués, "Introducción”, en Tomás de Aquino, Exposición del De Trinitate de Boecio, 1986, Pamplona, EUNSA, pp. 14-15.

${ }^{16}$ Celada Luengo, op. cit., p. 179. 
el De secretis secretorum, el primero de Proclo y el segundo de un filósofo árabe del siglo XI. Esto es prueba de que el Aquinate estaba familiarizado con el estilo y la argumentación aristotélica. ${ }^{17}$

La orden dominicana no quedó exenta de las prohibiciones de algunas doctrinas de Aristóteles. En el Capítulo de 1243, siguiendo el consejo de algunos profesores insignes de la Universidad de París, prescribieron la eliminación de doctrinas perniciosas emparentadas con Aristóteles y de las posturas novedosas de los filósofos árabes y judíos. ${ }^{18}$

Al parecer, el primer contacto del Aquinate con Aristóteles fue en la Universidad de Nápoles. Después se encontró con Alberto Magno en París y luego en Alemania. En sus años de estudiante como bachiller sentenciario, Tomás de Aquino encontró un ambiente no muy favorable por la presión de los pensadores ortodoxos que seguían en sus clases textos fijos y manuales consagrados para la enseñanza, sin permitir la intromisión de las innovaciones filosóficas aristotélicas. ${ }^{19}$

En 1255 se estableció oficialmente la enseñanza de las categorías aristotélicas en la Universidad de París, ya no había autoridad humana alguna que lo impidiera. En 1265, el papa Clemente IV alentó al dominico Guillermo de Moerbeke para que tradujera las obras aristotélicas que hasta el momento habían estado prohibidas. Este trabajo fue muy bien aprovechado por los estudiosos, que contaron en adelante con traducciones concienzudas y fieles al espíritu de Aristóteles. ${ }^{20}$ En tiempos de Urbano V (1362) se exigía a los candidatos al grado de licenciado en Artes, que conocieran suficientemente todas las obras de Aristóteles para no desviarse de la sana doctrina y estar mejor preparados para los estudios teológicos.

${ }^{17}$ Antes de Tomás de Aquino, la fe y la razón eran todavía dos realidades estrechamente unidas, pero independientes. El influjo y el recurso al sentido aristotélico de la ciencia era un reto para la teología, si quería seguir siendo creíble, de ahí la obligación académica de aceptar las novedades aristotélicas y dotarse así de nuevos sistemas de enseñanza.

${ }^{18}$ Fruto de las controversias contra los musulmanes, Tomás de Aquino escribió el De unitate intellectus contra averroistas, opúsculo editado en París en 1270, en el cual refuta la interpretación averroísta del texto aristotélico Sobre el alma.

${ }^{19}$ Eudaldo Forment, Historia de la filosofia II. Filosofia medieval, 2014, Madrid, Palabra, p. 270.

${ }^{20}$ En Roma se encontraron Alberto Magno, Tomás de Aquino y Guillermo de Moerbeke. Ahí se pusieron de acuerdo para realizar la traducción del griego de los textos de Aristóteles. 
La revolución intelectual de Alberto Magno

y Tomás de Aquino

El enfrentamiento de la filosofía árabe y judía con el cristianismo académico de las universidades de Occidente provocó una conmoción que en lugar de ser un factor negativo, suministró un fecundo arsenal de materiales intelectuales a los escolásticos latinos. Hay que reconocer que en esa época, la enseñanza de la filosofía había caído en discusiones puramente lógicas y en interpretaciones muy limitadas que rayaban en meras repeticiones. Además, el agustinismo, lleno de un vano platonismo, había cansado a los grandes maestros medievales. ${ }^{21}$

Sin duda, como decimos desde el ámbito científico, integrar la doctrina aristotélica a los estudios eclesiásticos supuso realmente una "revolución intelectual", es decir, una ruptura de paradigmas filosóficos. A partir de esta época se dejó de hablar de independencia de la fe y la teología católica respecto de la doctrina metafísica y ética de Aristóteles. Los frutos serán magníficos, tanto desde el punto de vista metodológico como dogmático. La Lógica aristotélica que reinaba en las universidades dejó el lugar a la completa doctrina aristotélica. Es impresionante imaginar a aquellos académicos medievales quedar con los ojos abiertos y maravillados con la enseñanza de Aristóteles. Sin duda tenían en sus manos una veta inexplorada de un autor de la Antigüedad que había logrado el más alto desempeño intelectual al que puede llegar la mente humana. Así comenzó la aventura de estructurar y concatenar la razón con la Revelación, de tal forma que en Aristóteles encontraron al más grande de todos los filósofos, es decir, al Filósofo, tal como lo llamaba Tomás de Aquino.

La genialidad del Aquinate consistió en haber articulado armónicamente las principales categorías aristotélicas con la fe católica. El influjo determinante de Aristóteles sobre Tomás de Aquino se dio en su formación temprana en las aulas del studium generale de Nápoles, donde proliferaban los textos de los filósofos griegos como una novedad

${ }^{21}$ María del Carmen Dolby, "Introducción”, en El hombre es imagen de Dios. Visión antropológica de San Agustín, 2002, Pamplona, EUNSA, p. 17. 
académica. ${ }^{22}$ Sin duda, Alberto Magno ejerció un magisterio decisivo. Gracias a él, Tomás de Aquino adquirió el respeto y la estima por Aristóteles.

El ejemplo de san Alberto fue para el Aquinate baluarte de un trabajo intelectual paciente, sereno, sin miedos y deseoso de encontrar la verdad en medio de las contradicciones. Lo que distingue al mediocre del académico es la honestidad intelectual. En este contexto, Tomás de Aquino llevó a cabo en silencio una de las mayores revoluciones doctrinales de la historia, al sustituir la escolástica medieval cerrada al progreso, por una escolástica viviente y fecunda en el contacto con Aristóteles y, además, las aportaciones neoplatónicas. El trabajo académico del Aquinate seguramente dejó a muchos de sus contemporáneos impresionados por su sutileza al disputar e interpretar con claridad las nociones nucleares de la metafísica. ${ }^{23}$

La orden dominicana convocó a Tomás de Aquino para que fuera profesor en la Universidad de París. A la edad de 27 años, enseñó teología en un ambiente de constante oposición entre los profesores. ${ }^{24} \mathrm{El}$ Aquinate se encontraba solo en una situación muy compleja, porque no tenía alumnos competentes o de su talla intelectual, y porque muchos de sus colegas se preocupaban tanto por custodiar la herencia cristiana que se olvidaban de lo que realmente valía la pena. Tomás de Aquino no se desanimó ni detuvo su estudio de la doctrina aristotélica, a pesar de ser incomprendido por los de su tiempo.

Josef Pieper señala que en la Universidad de Toulouse se enseñaba la doctrina aristotélica y que en su propaganda de ingreso se decía que ahí estaba permitido lo que en la Universidad de París estaba prohibido. ${ }^{25}$ En 1245, Tomás de Aquino se fue a París, después de haber estudiado la Ética Nicomaquea en Nápoles de la mano directa de Alberto Magno. En 1254 el Aquinate escribió su primer opúsculo, De ente et essentia, cuyo primer capítulo empieza con una cita de la Metafísica. Además,

${ }^{22}$ Hay que recordar que Tomás de Aquino dejó la abadía benedictina de Montecasino a la edad de 15 años para ingresar a la orden de los dominicos. En la Universidad de Nápoles aprendió a esa corta edad conceptos nuevos y una visión distinta de ver la realidad.

${ }^{23}$ Fraile, op. cit., pp. 265-266.

${ }^{24}$ Josef Pieper, Introducción a Tomás de Aquino. Doce lecciones, 2005, Madrid, Rialp, p. 25.

${ }^{25}$ Ibid., p. 54. 
Aquino comenzó a llamar a Aristóteles el Filósofo (hay muchos filósofos, pero Aristóteles lo es por antonomasia). ${ }^{26}$.

Alberto Magno ya había realizado múltiples comentarios a las obras aristotélicas a pesar de las prohibiciones, y "digo a pesar", porque las pronunciaciones papales eran consideradas "prudenciales", y no contrarias a los dogmas de la Iglesia. Así, Alberto y Tomás fueron revolucionarios en el sentido de que por honestidad intelectual y amor a la verdad siguieron investigando a Aristóteles, siendo totalmente papistas, es decir, apegados a las enseñanzas de la Iglesia. Fueron los precursores de los que invalidaron las prohibiciones. Junto con Alberto y Tomás hay que colocar a Pedro de Hibernia. Como "profesores modernos", fueron pensadores que asumieron una filosofía aristotélica no depurada, sino en una forma tachada de extremista y peligrosa. Tomás de Aquino perfeccionó la dialéctica de su maestro Alberto Magno, sosteniendo la legitimidad y la utilidad de la filosofía en la cultura cristiana y en particular la función del aristotelismo en el campo teológico. ${ }^{27}$

Otra idea que se ha malinterpretado en la historia del tomismo es la afirmación de que Tomás de Aquino es un aristotélico en el sentido pleno de la palabra. Para dar un ejemplo de lo anterior, hay que recordar el tratado de Joseph Gredt Elementa philosophiae aristotelico-thomisticae (1901), que denota un reduccionismo evidente, o bien las imputaciones de ser el "fundador del aristotelismo cristiano de la Edad Media". En mi opinión, el Aquinate es mucho más que eso. Hay en el pensamiento tomasiano rasgos esenciales tomados no solo de Aristóteles, sino también de Platón, Agustín, Dionisio Areopagita, etc.; y muchas veces con mayor presencia y profundidad que el Estagirita. De hecho, por Tomás conocemos muchos errores de Aristóteles respecto a Platón. ${ }^{28}$ Las frases características que utilizó el Aquinate son: "como quería decir tal", p. 113.

${ }^{26}$ Emerich Coreth, Dios en la historia del pensamiento filosófico, 2006, Salamanca, Sígueme,

${ }^{27}$ Raimondo Spiazzi, Santo Tomás de Aquino. Biografia documentada de un hombre bueno, inteligente, verdaderamente grande, 2005, Madrid, Edibesa, p. 119.

${ }^{28}$ De Platón, Tomás de Aquino tomó la doctrina de las ideas, la concepción de la Creación según las razones seminales, el logos divino, que son aspectos nucleares de la doctrina platónica que jamás desechó el Aquinate. Sensatamente, Tomás como académico, asumió el pensamiento platónico que había pervivido en mil años de pensamiento en Occidente. 
"el auténtico sentido", "la verdadera interpretación". Ciertamente, su principal inclinación fue hacia Aristóteles, dadas las circunstancias culturales en las que se encontraban en el camino especulativo la religión y la filosofía. El dinamismo especulativo aristotélico fue irresistible para el Aquinate como para otros pensadores. No era un autor cualquiera, sino un pensador metafísico que iluminaba sin precedentes los fenómenos psicológicos y cosmológicos. De hecho, hubo quien afirmó que Dios le había participado al filósofo macedonio de su sabiduría dándole una virtud milagrosa, como una propedéutica para relacionarlo con el Evangelio. ${ }^{29}$ Por supuesto, Tomás de Aquino adoptó una postura moderada respecto a la doctrina aristotélica y no rindió nunca un culto exagerado a Aristóteles.

Es pertinente notar que cuando el Aquinate se adhirió a tesis aristotélicas, no recibió algo totalmente extraño a la doctrina cristiana, pues la actitud aristotélica respecto a lo que es el mundo, el hombre y Dios tenía semejanzas con la teología católica. La autoridad de Aristóteles fue para Tomás esencial, no porque lo dijera Aristóteles mismo, sino porque correspondía adecuadamente a la realidad natural, a la forma como está dispuesta por la naturaleza, de ahí las palabras del Aquinate respecto a la autoridad aristotélica: sicut patet per Philosophum, que en español sería: "como lo ha puesto en claro Aristóteles", lo que "dice" el Estagirita es válido porque es verdadero. El Doctor Común tomaba el argumento de autoridad como el más débil de la argumentación. Para él la máxima fuerza de autoridad entre los cristianos procede de la Revelación. Los argumentos filosóficos son válidos no a causa de la autoridad de quienes los esgrimen, sino por lo que se ha dicho. ${ }^{30}$

Tomás se interesaba por "la verdad de las cosas", y buscaba los motivos por los cuales el Estagirita pensaba de esa manera. Así, su interés no era exclusivamente por el filósofo macedonio, sino por los pensadores que tuvieran qué aportar o a la verdad. Tal fue la postura de los pensadores medievales, y debe serlo en la actualidad. En el fondo, se trata de la búsqueda de las fuentes que sustenten nuestras opiniones. ${ }^{31}$

${ }^{29}$ Pieper, op. cit., p. 59.

${ }^{30}$ San Agustín, In Trin., 2, 3 ad 8.

${ }^{31}$ Eudaldo Forment, Santo Tomas de Aquino: Su vida, su obra y su época, 2009, Madrid, BAC, p. 207. 
Coincidencias y diferencias entre Alberto Magno y Tomás de Aquino

Según Josep-Ignasi Saranyana, Alberto y Tomás coinciden en las siguientes tesis: ${ }^{32} 1$. Todas las criaturas están compuestas de quod est $\mathrm{y}$ esse. Solo en el Creador su quod est es su esse. 2. La materia prima es pura potencia. Ni es inteligible en sí misma ni existe por sí, pues en cuanto tal, excluye cualquier formalidad. 3. En todos los seres compuestos, sin excluir al hombre, la forma substancial es única. 4. Es contradictoria la idea de una materia espiritual. Por consiguiente, es imposible el hilemorfismo universal, si se admite que existen seres espirituales distintos de Dios. 5. Ambos destacan la superioridad de la inteligencia sobre la voluntad, pues nada puede ser querido que no haya sido previamente conocido; aunque reconocen que, en el actual estado de la vida, muchas veces la voluntad tiene cierto dominio sobre la inteligencia. 6. Los dos sostuvieron que el conocimiento, sobre todo en los estadios más altos de la unión mística, ocurre sin la mediación de fantasmas o imágenes, pero nunca sin especies. En el arrebato, las especies son estrictamente intelectuales en cuanto a su origen, es decir, no provienen de un proceso de abstracción. ${ }^{33}$

Hay que recordar que Tomás de Aquino recibió gran parte de su formación filosófico-teológica de Alberto Magno en tres largos años de intensa actividad académica en París, de 1245 a 1248. Además, en Colonia (1248-1252) el Aquinate lo escuchó comentar ampliamente las Sentencias de Pedro Lombardo y la Ética Nicomaquea, así como libros del Antiguo y Nuevo Testamento. Fueron siete años en los que Tomás de Aquino aprendió el método y la sutileza de Alberto, tanto como el amor a la verdad. El Aquinate, con su intuición, confirmada por las enseñanzas de Alberto Magno en varias ocasiones, comprendió la importancia de la filosofía aristotélica y lamentó que fuera excluida de las universidades católicas. La historia todavía no les reconoce de manera suficiente a Alberto y Tomás el gran mérito de haber sido los precursores del ingreso de Aristóteles en el pensamiento cristiano.

${ }^{32}$ Josep-Ignasi Saranyana, La filosofía medieval, 2003, Pamplona, EUNSA, pp. 259-258.

${ }^{33}$ José Ángel García Cuadrado, "La luz del intelecto agente en el pensamiento de San Alberto", en Revista Española de Filosofia Medieval 9 (2002), p. 95. 
En el mismo orden del párrafo anterior, señalemos ahora las diferencias o discrepancias entre los pensadores, siguiendo de nuevo a Saranyana: ${ }^{34}$ 1. Alberto Magno identificaba ser eterno con ser increado. Por ello, estimaba que es contradictorio un mundo eterno creado. Para el Aquinate, en cambio, eterno no significaba increado, sino no haber tenido principio en el tiempo. De ahí se podía pensar, desde el punto de vista metafísico, en un ser creado desde toda la eternidad. 2. Alberto Magno no identificó a los ángeles con las sustancias separadas de la filosofía peripatética, responsables del movimiento de las esferas celestes. Tomás de Aquino, en cambio, aceptó que los ángeles podían ser las sustancias separadas de los filósofos, que mueven las esferas celestes, y consideró que solo por vía de la Revelación se puede conocer que los ángeles son seres personales, mensajeros de Dios, que están a su servicio. 3. Alberto Magno pensó que el proceso de maduración del embrión humano era progresivo, de manera que en el origen de tal desenvolvimiento estaba ya todo, incluso la misma inteligencia. El Aquinate, en cambio, estimó que el embrión humano solo llega a ser un individuo de la especie humana por medio de sucesivas generaciones y corrupciones, es decir, después de varios cambios sustanciales, el más importante de los cuales consiste en la infusión del alma espiritual al cabo de unas pocas semanas después de la fecundación. 4. Ambos pensadores discreparon también en el tema de la composición ontológica o metafísica del ente finito. Alberto Magno entendió que el esse sobrevenía a la esencia como algo extrínseco a ella y, de algún modo, accidental. Tomás de Aquino afirmó, en cambio, que el esse es algo añadido a la esencia de la cosa, constituido a partir de los principios esenciales, que no pertenece a la esencia misma de la cosa ni es accidental. ${ }^{35}$

Alberto Magno gozaba de un enorme prestigio entre sus contemporáneos, que por eso lo llamaban el "Grande". Por su conocimiento de Aristóteles se le consideraba una autoridad frente a Avicena y Averroes y la historia de la filosofía lo reconoce como el que supo integrar la ciencia y el pensamiento cristiano. Su acervo cultural fue impresionante y explicó con un nuevo método las obras de Aristóteles. De este modo,

${ }^{34}$ Saranyana, op. cit., pp. 261-262.

${ }^{35}$ Josep Pieper, Filosofía medieval y mundo moderno, 1973, Madrid, Rialp, p. 309. 
en lugar de seguir el orden del libro y ceñirse al texto, estableció una nueva ordenación lógica y pedagógica, comentando cada párrafo puntualmente, para matizar y distinguir errores y desviaciones. Fue el método que adoptó Tomás de Aquino. ${ }^{36}$ La obra albertiana es más que una enciclopedia sistemática y coherente. Su mérito fue distinguir claramente, por primera vez, entre el orden natural, propio del saber filosófico, y el sobrenatural, al que pertenece la teología. Como teólogo, comprendió que no hay argumentos estrictamente demostrativos de los misterios de la Revelación. Finalmente, gracias a Alberto Magno, Tomás de Aquino pudo realizar la síntesis filosófico-teológica más grande.

\section{Diferencias entre Aristóteles y Tomás de Aquino}

Para este apartado seguiré al dominico Gregorio Celada Luengo, que habla de las diferencias esenciales entre estos pensadores. ${ }^{37}$ Es verdad que, aunque Tomás de Aquino fue un gran comentarista de Aristóteles, esto no quiere decir que confundiera sus posiciones doctrinales. La primera diferencia es en lo referente al acto creador, que se desprende a partir del significado religioso que tiene para la tradición judeocristiana. Aquí el Aquinate corrigió al Estagirita y amplió su visión con esta perspectiva. En concreto, la enseñanza divina no hace más que confirmar lo que implica afirmar que si solo Dios existe por sí, necesario y eterno, todos los otros seres, que son sus criaturas, existen por él y dependen de él. En este punto, la teología se sobrepone y corona el edificio metafísico. Tomás se mantuvo fiel a la sabiduría cristiana, más que a las elucubraciones aristotélicas. ${ }^{38}$

Una segunda diferencia es la doctrina sobre la visión beatífica, que desde el ámbito de la ética, abre los horizontes de una moral más completa, que no se puede percibir en las propuestas de vida filosóficas. Un ejemplo es que para Aristóteles la esfera de la felicidad se encontraba en

${ }^{36}$ Forment, op. cit., p. 208.

${ }^{37}$ Celada Luengo, op. cit., pp. 189-193.

${ }^{38}$ M. Grabmann, "Esencia y significación del aristotelismo de S. Tomás de Aquino", Ciencia Tomista, 67 (1944), p. 325. 
esta vida, mientras que para el dogma cristiano, el conocimiento de Dios está en la bienaventuranza. En el ámbito de las virtudes, el Aquinate se sirvió ampliamente de la ética formulada por el Estagirita, pero no descartó todo cuanto pueda decirse de la grandeza de ánimo de los hombres que son ejemplos de la humanidad, sino que impregnó su comentario del espíritu cristiano al héroe humano, según el principio de que la gracia perfecciona la naturaleza. Por ello, para el teólogo todo hombre tiende a la identificación del Dios de Jesucristo, incluso sin conocerlo. Tomás de Aquino aprovechó los conceptos de Aristóteles para fundamentar la moral cristiana, pero en muchos casos hizo profundas modificaciones y hay elementos transformados radicalmente. El Aquinate, como deudor de la sabiduría antigua, realizó un discernimiento concienzudo de lo que tuviera afinidades con la doctrina católica. ${ }^{39}$

Tomás de Aquino recogió como propia la doctrina aristotélica sobre la lógica formal, los conceptos de acto, potencia, materia, forma, causas, la división de las ciencias y su concepción del conocimiento científico. Compartía con el Estagirita el intelectualismo psicológico y moral, el indeterminismo moral, la doctrina del libre albedrío, la doctrina de la abstracción y el del conocimiento sensible, las pruebas de la existencia de Dios y sus atributos. ${ }^{40}$

Por último, hay que decir que Aquino modificó considerablemente muchas doctrinas de Aristóteles, como la distinción real de esencia y existencia en lo creado (por el creacionismo que desconocía el Estagirita), la distinción esencial entre Dios y las creaturas (por la trascendencia divina), las pruebas de la inmortalidad del alma. En otras doctrinas hay matices que no cambiaron en lo esencial las enseñanzas de Aristóteles, como el principio de individuación de la materia, el intelecto agente personal y la estructura ontológica de las sustancias separadas, entre otras. Por supuesto que no podemos ser anacrónicos, pues hay factores propios del tiempo, como las distintas circunstancias históricas y culturales en que vivieron cada uno, la diferente formación personal y los distintos modos de vida. Asimismo, los comentarios del Aquinate

${ }^{39}$ Étienne Gilson, El tomismo. Introducción a la filosofía de S. Tomás de Aquino, 1950, Buenos Aires, Descleé de Brouwer, p. 544.

${ }^{40}$ A. Messer, Historia de la filosofía, 1939, Buenos Aires, Espasa Calpe, p. 284. 
también difieren de otros pensadores católicos, de ahí que no sea arriesgado decir que Tomás de Aquino no quiso comentar a Aristóteles solo pensando por su propia cuenta, sino siendo fiel a su pensamiento. ${ }^{41}$

\section{Los comentarios de Tomás de Aquino a Aristóteles}

Menciona Celina A. Lértora que los comentarios a Aristóteles que se elaboraron durante el siglo XIII, persiguen tres objetivos primordiales: ${ }^{42}$ 1. Didácticos. Este fue el objetivo inicial de las universidades medievales, aplicando rígidos esquemas de trabajo docente. 2. Expurgativos. Como los pensadores escolásticos querían mantenerse fieles a la Revelación o a la enseñanza de la Iglesia, acogieron de buena gana la tarea de expurgar o hacer concordar a Aristóteles con las verdades de fe, convencidos de que podrían aprovechar los recursos especulativos de la ciencia aristotélica. 3. Filosóficos. La propuesta era explicitar y exhibir las conexiones y las consecuencias internas de las teorías aristotélicas; para lograr este objetivo, hay que tener en cuenta la capacidad intelectual y la sagacidad de cada comentador.

Tomás de Aquino se dio a la tarea de comentar las obras aristotélicas entre 1266 y 1273 . Fueron catorce obras las que comentó, de manera total o parcial, en esta etapa madura y final de su vida. En realidad, el Aquinate ya había estudiado a Aristóteles muchos años atrás y lo había citado en innumerables obras propias; la lectura de las "fuentes" era habitual y obligatorio para todos los estudiantes en las universidades del tiempo.

Exceptuando las Categorías, los Primeros analíticos, los Tópicos y las Refutaciones sofisticas, las grandes Morales, la Ética a Eudemo, la Poética y la Historia de los animales, Tomás de Aquino comentó todas las obras de Aristóteles. ${ }^{43}$ Los comentarios del Aquinate son considerados entre los más instructivos y profundos de la filosofía. Fueron la última

${ }^{41}$ Minio Paluello, "Note sull'Aristotele latino medievale", Rivista di Filosofia Neo-scolastica, 42 (1950), p. 223.

${ }^{42}$ Celina A. Lértora Mendoza, "Estudio preliminar", en Tomás de Aquino, Comentario a la Ética a Nicómaco de Aristóteles, 2000, Pamplona, EUNSA, p. 20.

${ }^{43}$ D. Barbedette, Historia de la filosofia, t. 1, 1976, México, Tradición, p. 343. 
ocupación importante de su vida, seis años de intensa actividad y rapidez en la escritura. En cuanto al método y técnica de los comentarios, el Aquinate no fue original ni el inventor de esa hermenéutica filosófica, sino que llevó a la práctica el método de Alberto Magno que ya se aplicaba en la Universidad de París, en la Facultad de Artes. Tomás de Aquino quería entender el propósito de Aristóteles y ejercitar la intuición para manifestar la verdad de cada texto.

La fuente principal de la filosofía tomista se encuentra en esos comentarios. De ahí sacó Tomás los principios, corrigió las consecuencias y modificó los sistemas de la filosofía griega. Fue un trabajo majestuoso, y más, por la situación cultural de la época. Para esta tarea, el Aquinate tuvo en sus manos versiones latinas fieles del original griego.

\section{Conclusión}

Los comentarios filosóficos del Aquinate son considerados una parte importante de su producción literaria, no son meras "repeticiones" de Aristóteles, sino auténticos aportes a su propio sistema. Estos textos son expresión de su pensamiento maduro e incluyen la consideración de otros exégetas del Estagirita, como Avicena y Averroes. El Aquinate tenía un pensamiento "personal y original", cuya prueba es que en vida y después apenas tuvo discípulos y detractores. Algunas conclusiones:

Primera. No hay duda de que Tomás de Aquino reservaba para Aristóteles un estatuto de "interlocutor privilegiado". Mientras que a los demás filósofos los citaba por su nombre, a Aristóteles lo llamaba el Filósofo.

Segunda. Aunque tiene un respeto ejemplar por el Estagirita, no es más que una actitud habitual del Aquinate con todos los pensadores que lo han precedido, de los que en todo momento se siente deudor. Aristóteles ocupa un lugar importante, pero no es el único.

Tercera. Tomás de Aquino no es un ecléctico que le daba la razón a todo mundo para no tener problemas ni entrar en conflictos, sino que adoptó siempre una postura crítica y aun se distanció cuando fue preciso. 
Ahora bien, al tratarse de sus contemporáneos, utilizaba un lenguaje duro que no empleaba con los autores que solo conocía por sus textos.

Cuarta. El Aquinate no utilizaba la doctrina aristotélica según lo impusieran las conveniencias de la teología católica. No le hizo decir a Aristóteles lo que no estuviera en el texto.

Quinta: No es conveniente decir que Tomás de Aquino "bautizó" a Aristóteles, como exclaman los manuales tomistas exagerados, pues no es exclusivamente aristotélico. Es cierto que Tomás de Aquino conocía perfectamente la filosofía aristotélica y los puntos de convergencia con la teología católica, pero trataba de dar a la teología un estatuto científico dentro de la tradición.

Es lamentable que aun cuando muchos se llaman "tomistas" y haya publicadas numerosas exposiciones de su doctrina, parecen haberse eximido del contacto directo con sus obras. No menos penoso es la falta de "traducciones" de los comentarios a Aristóteles. Hasta se puede afirmar que muchos cristianos son culpables de que no se manifieste su pensamiento original, por una mala interpretación de las tesis genuinas del Aquinate. Además, en muchos ambientes académicos los comentarios aristotélicos se han considerado la parte más débil de la obra de Tomás. Por mi parte, considero que estos comentarios son el andamiaje sin el cual el resto de su doctrina, incluida la metafísica, no se puede comprender de manera exacta. 
CITAM Derechos Reservados.

La reproducción total o parcial de este artículo se podrá hacer si el ITAM otorga la autorización previamente por escrito. 